\title{
BMJ Open Glycaemic control and antidiabetic treatment trends in primary care centres in patients with type 2 diabetes mellitus during 2007-2013 in Catalonia: a population-based study
}

\author{
Manel Mata-Cases, ${ }^{1,2,3}$ Josep Franch-Nadal, ${ }^{1,2,4}$ Jordi Real, ${ }^{1,5}$ \\ Dídac Mauricio ${ }^{1,2,6}$
}

To cite: Mata-Cases M, Franch-Nadal J, Real J, et al. Glycaemic control and antidiabetic treatment trends in primary care centres in patients with type 2 diabetes mellitus during 2007-2013 in Catalonia: a population-based study. BMJ Open 2016;6: e012463. doi:10.1136/ bmjopen-2016-012463

- Prepublication history and additional material is available. To view please visit the journal (http://dx.doi.org/ 10.1136/bmjopen-2016012463).

Received 29 April 2016 Revised 3 August 2016 Accepted 13 September 2016

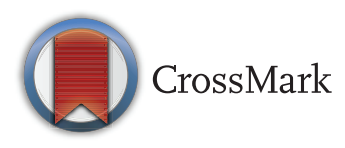

For numbered affiliations see end of article.

Correspondence to Dr Dídac Mauricio; didacmauricio@gmail.com

\section{ABSTRACT}

Objectives: To assess trends in prescribing practices of antidiabetic agents and glycaemic control in patients with type 2 diabetes mellitus (T2DM).

Design: Cross-sectional analysis using yearly clinical data and antidiabetic treatments prescribed obtained from an electronic population database.

Setting: Primary healthcare centres, including the entire population attended by the Institut Català de la Salut in Catalonia, Spain, from 2007 to 2013.

Participants: Patients aged 31-90 years with a diagnosis of T2DM.

Results: The number of registered patients with T2DM in the database was 257072 in 2007, increasing up to 343969 in 2013 . The proportion of patients not pharmacologically treated decreased by $9.7 \%(95 \% \mathrm{Cl}-9.48 \%$ to $-9.92 \%)$, while there was an increase in the percentage of patients on monotherapy $(4.4 \%$ increase; $95 \% \mathrm{Cl} 4.16 \%$ to $4.64 \%)$, combination therapy $(2.8 \%$ increase; $95 \% \mathrm{Cl}$ $2.58 \%$ to $3.02 \%$ ), and insulin alone or in combination (increasing 2.5\%; $95 \% \mathrm{Cl} 2.2 \%$ to $2.8 \%$ ). The use of metformin and dipeptidyl peptidase-IV inhibitors increased gradually, while sulfonylureas, glitazones and $\alpha$-glucosidase inhibitors decreased. The use of glinides remained stable, and the use of glucagon-like peptide-1 receptor agonists was still marginal. Regarding glycaemic control, there were no relevant differences across years: mean glycated haemoglobin ( $\mathrm{HbA1c})$ value was around $7.2 \%$; the percentage of patients reaching an $\mathrm{HbA} 1 \mathrm{c} \leq 7 \%$ target ranged between $52.2 \%$ and $55.6 \%$; and those attaining their individualised target from $72.8 \%$ to $75.7 \%$.

Conclusions: Although the proportion of patients under pharmacological treatment increased substantially over time and there was an increase in the use of combination therapies, there have not been relevant changes in glycaemic control during the 2007-2013 period in Catalonia.

\section{Strengths and limitations of this study}

- The main strength of the study is the use of a large outpatient database that is indicative of the trends of general practitioners' practices in a real-life clinical setting.

- However, this was a retrospective study participant to errors in data recording or missing values.

- We were not able to assess whether the change in prescribed treatments over time was driven by patients' needs and characteristics (eg, prior low tolerability or effectiveness), and we cannot therefore claim a causal effect.

- We could not assess whether doses of pharmacological treatments were appropriately chosen, and we did not consider data on prescriptions within the same therapeutic class.

\section{INTRODUCTION}

Type 2 diabetes mellitus (T2DM) is a highly prevalent chronic disease at risk of chronic microvascular and macrovascular complications when glycaemic control is suboptimal. ${ }^{1}$ Although diet and lifestyle changes are initially effective, most patients will need an oral glucose-lowering agent to better control blood glucose levels, and most will eventually need multiple therapies as the disease progresses. ${ }^{2}$ The pharmacological armamentarium to treat hyperglycaemia in T2DM has changed substantially over the past 20 years with the development of new therapeutic agents, such as insulin secretagogues (glinides), thiazolidinediones, incretins (glucagonlike peptide-1 receptor agonists (GLP-1ra) and dipeptidyl peptidase-IV inhibitors (DPP4i)), sodium-glucose transporter-2 inhibitors, fixeddose combinations, and also with the advent of 
insulin analogues. ${ }^{3}$ This, together with changing treatment recommendations advocating for an intense glycaemic control in early stages of the disease,${ }^{45}$ makes drug choice increasingly challenging, and it has driven substantial changes in current prescribing practices with wide variations between countries depending on each therapeutic class. $^{6-17}$

General practice databases are a reliable and rich source of information from the general population, and therefore a valuable tool to study medical practice in the community. ${ }^{18}$ In Catalonia, Spain, such an electronic general practice database is available for researchers (Information System for the Development of Research in Primary Care (SIDIAP)), and it has been previously used to conduct several observational studies to assess different aspects of the natural history and treatment of T2DM in our autonomous region. ${ }^{19-26}$

In the present study, we aimed to examine prescribing patterns for antidiabetic treatment in primary care in Catalonia between 2007 and 2013 using SIDIAP data, and how changes impacted the degree of attained glycaemic control over time.

\section{MATERIALS AND METHODS \\ Design}

This was a cross-sectional, retrospective study using the SIDIAP database, which started in 2006 and stores data from electronic medical records. The database contains anonymised longitudinal patient information obtained from the electronic clinical records using specific software (Electronic Clinical station in Primary Care, eCAP) developed by the institution and used since 2001 by all of the 274 primary care centres pertaining to the Catalan Health Institute (ICS), which attends $80 \%$ of the total population (about 5.835 million patients) in Catalonia.

\section{Data extraction}

Data from patients aged 31 to 90 years with a diagnosis of T2DM (by means of the International Classification of Diseases, 10th Revision (ICD-10) codes E11 or E14) were obtained from the SIDIAP database for the years 20072013. Data were extracted for patients for each particular year. As a dynamic database, new patients enter when a new diagnosis of T2DM is recorded, and patients are withdrawn when a death occurs or the patient moves to another healthcare region not served by the Catalonian Health Institute. Registered variables included: age; gender; time since diagnosis; the presence of comorbidities (ICD-10 codes); and the most recent value for each year of body mass index (BMI) and mean glycated haemoglobin (HbA1c). Before 1 January 2010, between $50 \%$ and $70 \%$ of laboratories in Spain expressed HbA1c values using the Japanese Diabetes Society/Japanese Society for Clinical Chemistry criteria (JDS/JCC; normal range 3.9$5.7 \%),{ }^{27}$ and these values were not converted to the internationally defined Diabetes Control and Complications Trial/National Glycohemoglobin Standardization
Program (DCCT/NGSP) calibration criteria (normal range 4-6\%). All values from 1 January 2010 onwards were expressed using DCCT/NGSP criteria.

The prescribed antidiabetic treatments for each patient and year were extracted from prescription-invoicing and pharmacy-invoicing data provided by the Catalan Health Service (CatSalut), which are incorporated yearly into the SIDIAP database. Glucose-lowering agents included the use of insulin and non-insulin antidiabetic drugs (NIADs) marketed in Spain during the study period, namely metformin, sulfonylureas, glinides, glitazones, DPP4i, GLP-1ra and $\alpha$-glucosidase inhibitors (AGI). The first DPP4i marketed in Spain was sitagliptin (2007) followed by vildagliptin (2007), saxagliptin (2010) and linagliptin (2012). For GLP-1ra, daily exenatide appeared in 2007, and liraglutide in 2011. Treatment steps were categorised as nonpharmacological treatment, an NIAD in monotherapy, NIADs in combination (2 or more without insulin), insulin alone or insulin in combination with NIADs.

\section{Statistical analysis}

Descriptive analyses by year are presented as mean and SD for continuous variables, and percentages for categorical variables. Changes across the study period were evaluated through the absolute overall increase and the 95\% CIs using the normal approximation. We used three different criteria for adequate glycaemic control: mean $\mathrm{HbA} 1 \mathrm{c} \leq 7 \%$, as widely recommended and accepted; $\mathrm{HbAlc} \leq 8 \%$, as recommended by our institution during the study period (ICS) $;^{28} 29$ and individualised goals based on age, duration of the disease, and presence of serious complications or comorbidities, as proposed by the Red de Grupos de Estudio de la Diabetes en Atención Primaria de la Salud 2014 (Red-GDPS).$^{30}$ All statistical calculations were performed using StataCorp 2009 (Stata Statistical Software: Release 11. College Station, Texas, USA: StataCorp, LP).

\section{RESULTS}

\section{Patients' characteristics}

The total number of registered patients with T2DM in our database was 257072 in 2007, increasing up to 343969 in 2013 (a total increase of 86897 cases) (table 1). The patients' mean age did not vary substantially over the years (overall increase 1.20 years; 95\% CI 1.14 to 1.26 years), and nor did the mean BMI or the number of obese patients (overall decrease $0.08 \mathrm{~kg} / \mathrm{m}^{2} ; 95 \%$ CI -0.11 to $-0.05 \mathrm{~kg} / \mathrm{m}^{2}$; overall $0.043 \%$ decrease in obese patients; $95 \%$ CI $-0.12 \%$ to $-0.74 \%$ ), but we observed a small progressive increase in the proportion of male patients (overall increase 2.15\%; $95 \%$ CI $1.90 \%$ to $2.40 \%$ ) , and also a gradual increase in the mean duration of the disease (overall increase 2.40 years; 95\% CI 2.37 to 2.43 years).

\section{Prescribing pattern of antidiabetic drugs}

The proportion of patients not receiving antidiabetic drugs decreased by $9.7 \%$ ( $95 \%$ CI $-9.48 \%$ to $-9.92 \%$ ) 


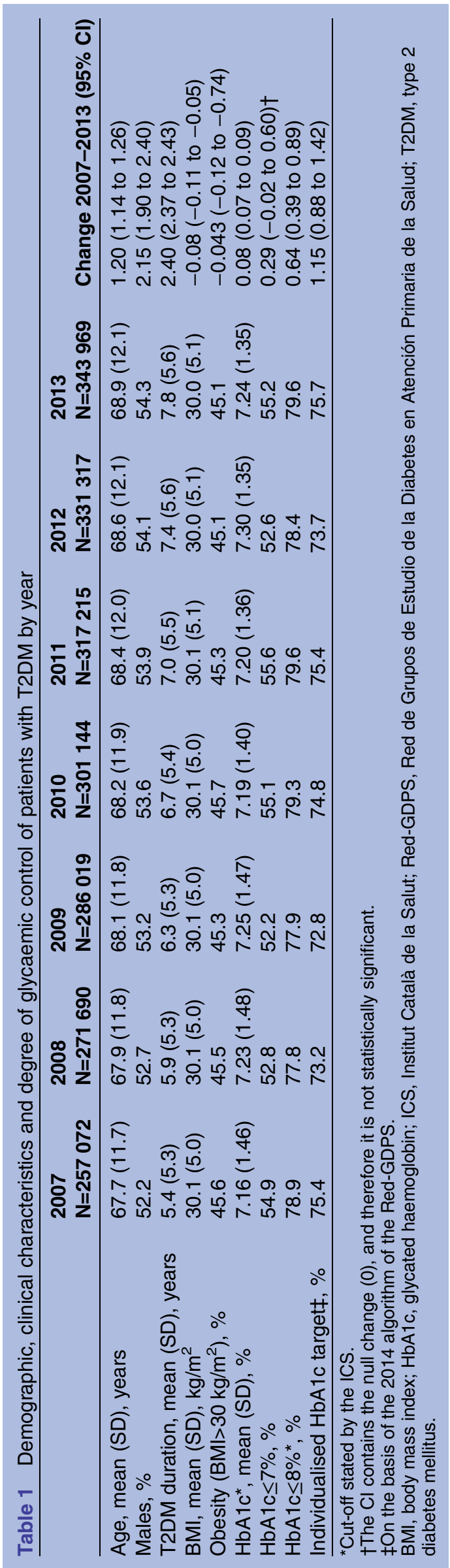

from 2007 to 2013, while the percentage of patients receiving pharmacological antidiabetic treatment was $71.9 \%$ in 2007 , and this proportion increased annually and was $81.6 \%$ in the last year of the study, showing an overall $9.7 \%$ increase over the study period. The proportion of patients receiving each type of therapy across the time period 2007-2013 is shown in figure 1. The most frequent prescription was an NIAD in monotherapy, the use of which increased $4.4 \%$ (95\% CI $4.16 \%$ to $4.64 \%$ ) from 2007 to 2013, followed by NIADs in combination (increasing $2.8 \%$; $95 \%$ CI $2.58 \%$ to $3.02 \%$ ), and insulin alone or in combination (increasing 2.5\%; 95\% CI 2.2\% to $2.8 \%$ ). Among NIADs, the most frequently used drugs were metformin and sulfonylureas, although the prescription rate of metformin increased notably across time $(19.5 \%$; $95 \%$ CI $19.25 \%$ to $19.75 \%)$, whereas it decreased gradually in the case of sulfonylureas $(8.20 \%$; $95 \%$ CI $-7.97 \%$ to $-8.43 \%$ ) (figure 2). As for the use of the rest of the available options, only the prescription of DPP4i increased substantially up to $13.2 \%$ in 2013 (95\% CI $13.09 \%$ to $13.31 \%$ ), while the use of glitazones, glinides, AGI and GLP-1ra remained low. Glitazones and AGI prescriptions even decreased with time: glitazones an overall $2.9 \%(95 \%$ CI $-2.82 \%$ to $-2.98 \%)$ and AGI $2.70 \%(95 \%$ CI $-2.62 \%$ to $-2.78 \%)$. Finally, glinides and GLP-1 ra only increased slightly over time: $0.8 \%$ in the case of glinides (95\% CI $0.69 \%$ to $0.91 \%$ ) and $0.9 \%$ in the case of GLP-1ra (95\% CI $0.87 \%$ to $0.93 \%$ ).

\section{Evolution of the degree of glycaemic control}

The mean standardised HbA1c value was around 7.2\%, with no clinically relevant differences across years (table 1 ). Moreover, the proportion of patients attaining a glycaemic target of $\mathrm{HbAlc} \leq 7 \%$ ranged from $52.2 \%$ to $55.6 \%$ (overall change $0.29 \%$; $95 \%$ CI $-0.02 \%$ to $0.60 \%$ ), and the ICS target $\leq 8 \%$ ranged from $77.8 \%$ to $79.6 \%$ (overall change $0.64 \%$; $95 \%$ CI $0.39 \%$ to $21.42 \%$ ), with no clinically relevant changes across years (table 1). Moreover, the percentage of patients attaining their individualised HbAlc target ranged increased by only $1.15 \%$ (95\% CI $0.88 \%$ to $1.42 \%$ ) (table 1 ). Finally, the analysis of the evolution of the attained glycaemic control according to different HbAlc intervals also showed that there were no remarkable changes among years in any case (figure 3). Of note, the group of patients who were less likely to achieve the corresponding glycaemic target included those younger than 65 years, without comorbidities, and duration of $\mathrm{T} 2 \mathrm{DM} \leq 15$ years (range $50.8-55.1 \%$ ) (see online supplementary table S1).

The evolution of the mean Hb1Ac levels according to each step of treatment and duration of T2DM is shown in figure 4 and online supplementary table S2. Considering all antidiabetic treatments, there was a progressive worsening of HbA1c levels as the disease duration increased, but this worsening was in fact only observed among patients treated with insulin alone or in combination with NIADs. Conversely, glycaemic values 
Figure 1 Percentage of patients with T2DM at each step of antidiabetic treatment. NIAD, non-insulin antidiabetic drug; T2DM, type 2 diabetes mellitus.

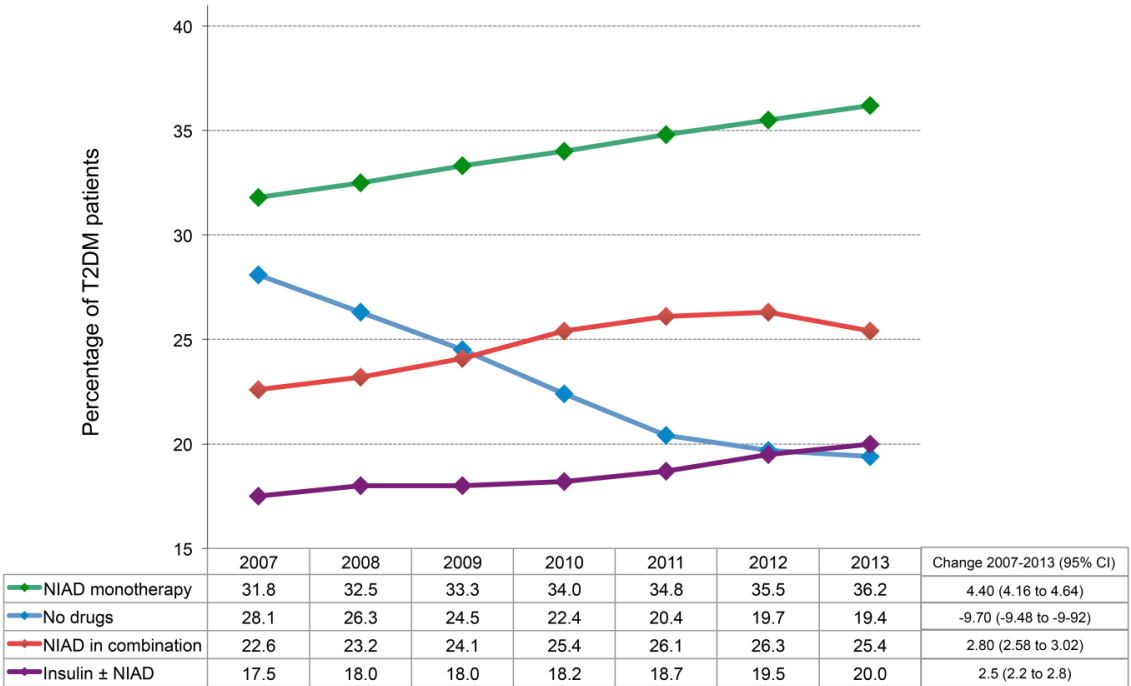

in patients not pharmacologically treated or on NIADs improved as T2DM duration increased, with no substantial differences across the study period.

\section{DISCUSSION}

This cross-sectional descriptive study is, to the best of our knowledge, the first to assess trends in the prescribing practices of antidiabetic drugs in relation to the level of attained glycaemic control between 2007 and 2013 in a primary healthcare setting in Spain.

A gradual increase in the prescription of antidiabetic agents has been previously reported in Spain ${ }^{16} 17$ and in studies conducted worldwide throughout the same or overlapping years as in our study. ${ }^{6-8} 10-123132$ An increase in the use of combinations of oral antidiabetic drugs (OADs) has been consistently observed in several studies from different countries, ${ }^{679111731}$ but the trends in its use as monotherapy vary among reports, with some describing an overall increase over time, ${ }^{11} 13 \quad 32$ and others a progressive decrease. ${ }^{6} 931$ Moreover, while the number of prescriptions of insulin in combination with an OAD has been shown to increase with time, ${ }^{6} 711$ the use of insulin alone has been reported to remain stable, $^{17} 33$ to decrease ${ }^{6} 1131$ or even to increase. ${ }^{32}$ Differences between drug schemes and studies may be attributable to health policy variations across countries, local professional expertise, physician's personal choice, study setting (eg, hospital vs primary care or insurance claims vs national database), or inclusion of both patients with T1DM and T2DM in some cases.

Both an increase in the use of metformin and a decrease in the use of sulfonylureas have been consistently reported by other groups. ${ }^{6-9} \quad 11-13 \quad 15 \quad 17$ 31-33 This decline could be related to the recent recommendation of cautionary use in the elderly, ${ }^{34}$ their worse safety profile, associated weight gain, unclear role in reducing long-term complications and/or to the availability of safer new therapeutic options. ${ }^{5}$ Although a decrease in glinides and AGIs use has been reported in Spain, Japan
Figure 2 Percentage of patients having non-insulin antidiabetic drug prescriptions (alone or in combination). AGI, $\alpha$-glucosidase inhibitors; DPP4i, dipeptidyl peptidase-IV inhibitors; GLP-1ra, glucagon-like peptide-1 receptor agonists; T2DM, type 2 diabetes mellitus.

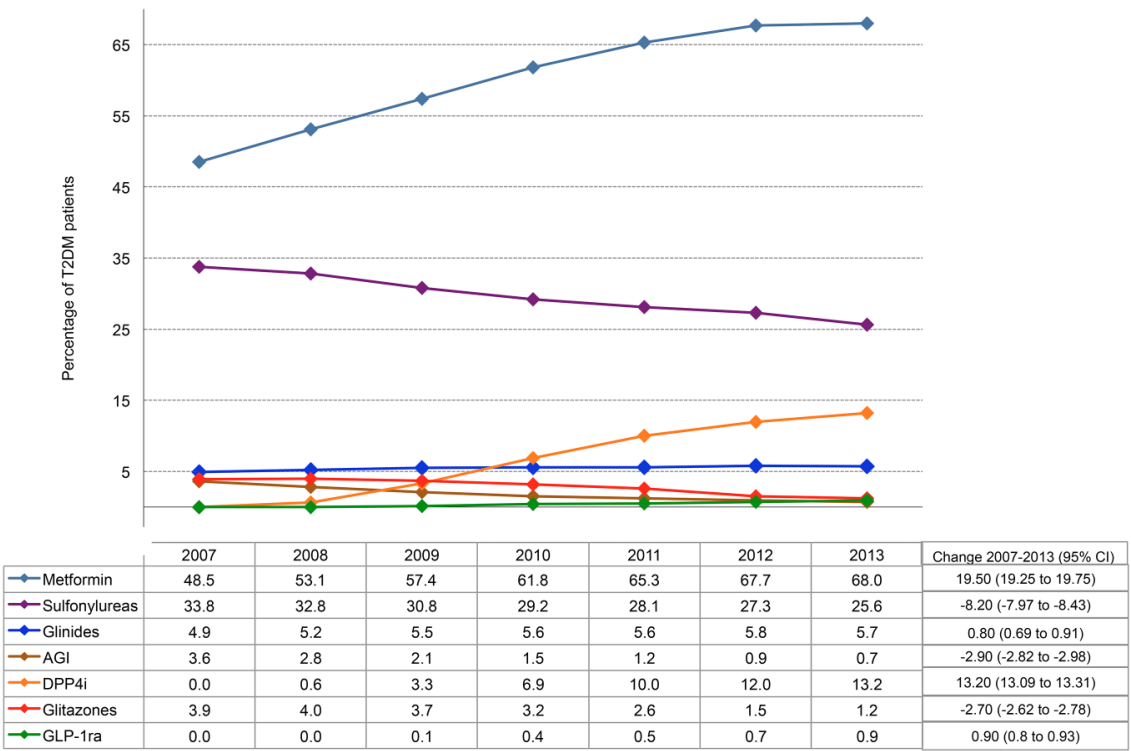


Figure 3 Percentage of patients achieving glycaemic control according to $\mathrm{HbA1c}$ intervals. $\mathrm{HbA1c}$, glycated haemoglobin; T2DM, type 2 diabetes mellitus.

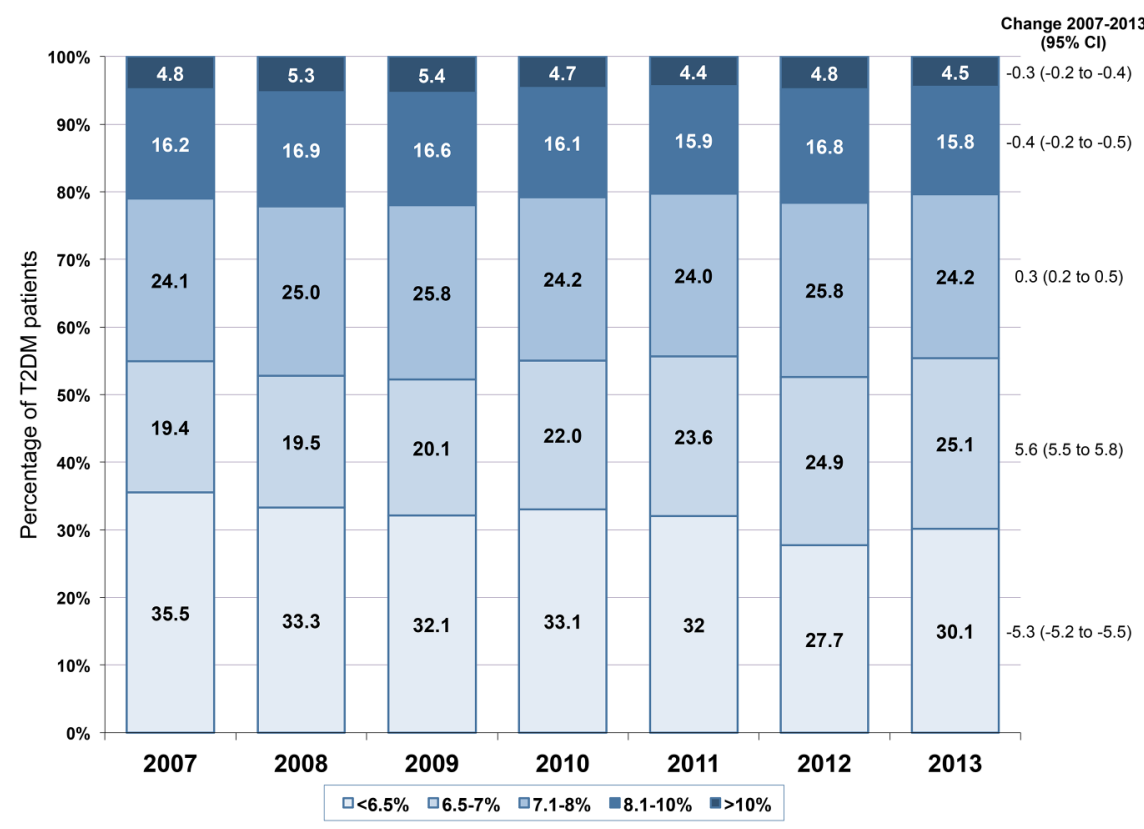

comparable effect in terms of glycaemic control, the physician's choice should be personalised based on patient's characteristics such as age, risk factors and comorbidities.

When we assessed the attained glycaemic control based on the treatment step, we found that patients on NIADs in combination or on insulin with or without an NIAD were the ones with the highest HbAlc levels. This is in line with the results of several studies showing a delay in treatment intensification in patients already on combination therapies whose control of blood glucose remained or became inadequate. ${ }^{35} 41$ Moreover, we found that about half of the patients had HbAlc levels $\leq 7 \%$ as recommended by clinical guidelines, about $80 \%$ below the $8 \%$ recommended by our institution (ICS), and about $75 \%$ below the individualised goal recommended by the Red-GDPS. Our figures are slightly worse than the ones reported by a study conducted in the Basque country in Spain for patients achieving HbA1c levels $\leq 7 \%$ (about $64.1 \%$ of them), but similar to their $85.5 \%$ of patients achieving a $\leq 8 \%$ target. $^{42}$ Finally, and confirming previous analyses, the subgroup with the highest proportion of patients attaining appropriate individualised glycaemic control was the one of patients older than 75 years, ${ }^{23}$ while patients younger than 65 years without comorbidities or serious complications and T2DM duration $\leq 15$ years were less likely to achieve the corresponding individualised glycaemic control target. This could be explained by a higher proportion of obesity among younger patients, a longer survival among adequately controlled older patients, or by an easier to reach glycaemic goal in the elderly $(\leq 8 \%$ vs $\leq 7 \%)$. More importantly, our results confirm that an individualised therapeutic approach considerably increases the chances of attaining adequate glycaemic control and provides effective T2DM care. ${ }^{43}$ However, one of the most striking 
All treatments
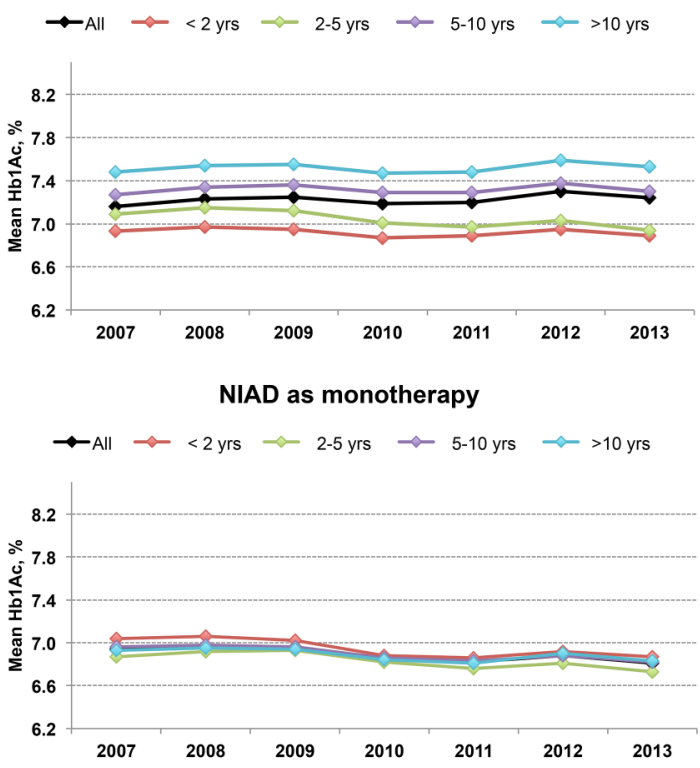

Insulin as monotherapy

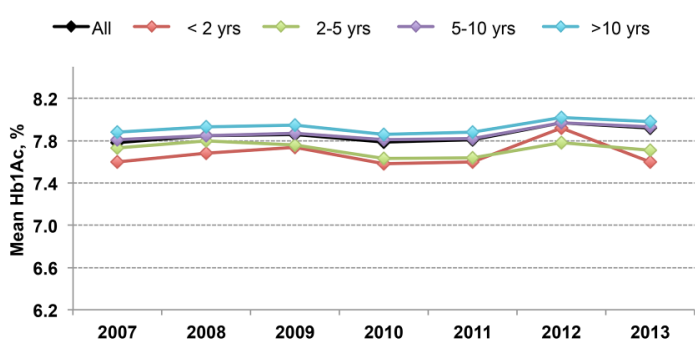

No drugs
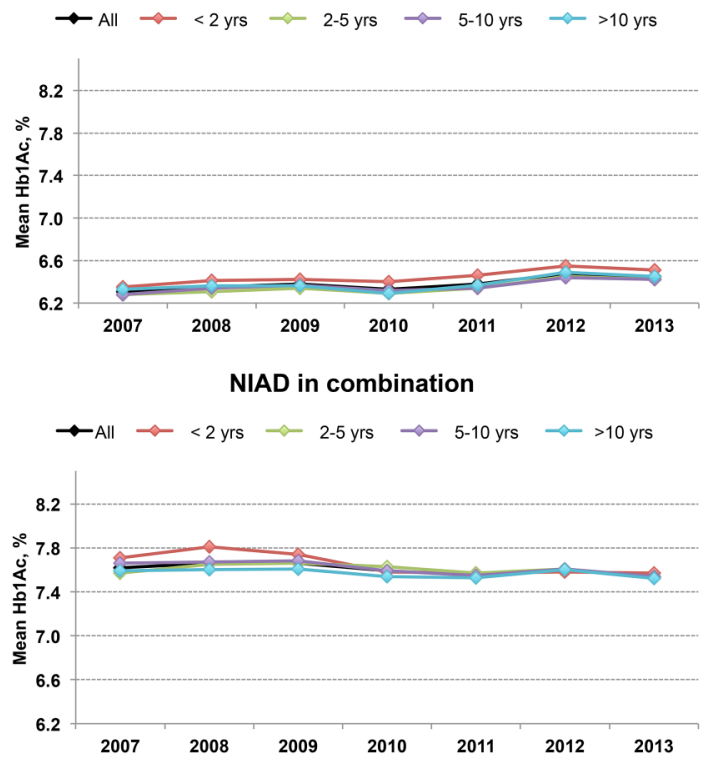

NIAD+insulin

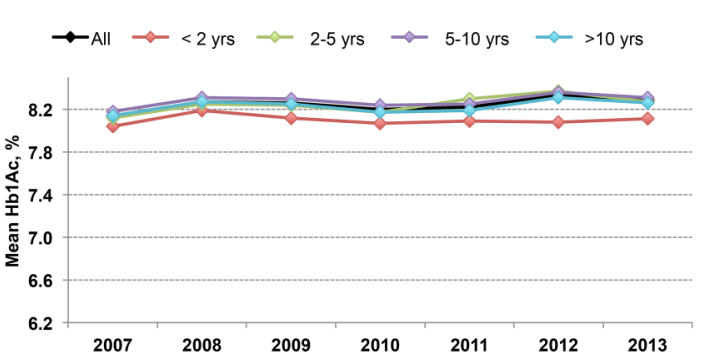

Figure 4 Evolution of mean $\mathrm{HbA1c}$ according to the different steps of antidiabetic treatment and T2DM duration. $\mathrm{HbA1c}$, glycated haemoglobin; NIAD, non-insulin antidiabetic drug; T2DM, type 2 diabetes mellitus.

findings of our study was that there were no relevant changes across years, meaning that in spite of the overall observed gradual increase in pharmacological treatments along the study there was no obvious trend towards an increase in the proportion of patients with an adequate HbAlc target whatever the used cut-off, and the mean HbA1c values did not significantly change over time regardless of the treatment step. There are few reports on how the evolution in the prescription pattern of antidiabetic drugs affects the level of attained glycaemic control, but our results are in contrast with a study conducted in Japan showing that the rate of patients achieving the $\leq 7 \%$ goal significantly improved together with the progressive increase in the proportion of pharmacological treatments. ${ }^{11}$ However, a very recent study conducted in Canada reported that the mean HbAlc values in older patients even increased slightly over a 5 -year period in spite of the overall increase in the use of antidiabetic treatment. ${ }^{14}$ Our results seriously question the ICS threshold to maintain HbA1c levels $\leq 8 \%$ for all patients, giving general practitioners financial incentives if this goal is attained, without taking into account age, diabetes duration or the presence of comorbidities. This threshold was established to avoid overtreatment-especially in the elderly-but can be counterproductive in younger patients. Certainly, about $25 \%$ of patients had HbAlc between $7.1 \%$ and $8 \%$, and were therefore at potential risk of suboptimal management or undertreatment until they reached this value, especially in people aged under 65 years. Thus, this institutional policy potentially contributes to therapeutic inertia, defined as a delay in treatment intensification among patients with poor glycaemic control. Clinical inertia has been documented in primary care settings, ${ }^{44} 45$ and a study conducted in Catalonia in 2007 in a sample of 2783 patients with T2DM reported that therapeutic inertia was present in $33.2 \%$ of cases, and treatment intensification was implemented in patients with a mean HbAlc of $8.4 \%,{ }^{41}$ which is far above the $8 \%$ threshold established by the institution. On the other hand, most family physicians find that patients treated with an NIAD combination but needing intensification with insulin or GLP-1ar, and those already on insulin needing optimisation with multiple insulin doses or the addition of a GLP-1ar, are difficult to manage or they have reasonable safety concerns. In these cases, clinical inertia is a major factor that contributes to inadequate glycaemic control in the long term. 
Our results show a global negative effect of T2DM duration on glycaemic control that did not change substantially across the study period. A progressive worsening of mean Hb1Ac values within each sequential evaluation might be expected because the proportion of patients with a disease duration $>10$ years increased, but this could have been counteracted by an intensified management in all treatment steps, eventually leading to steady mean HbA1c levels along the study. This is a possible explanation if we take into account that patients in the lowest treatment steps (ie, no drugs, and NIADs in monotherapy or combined) and with a disease duration $>10$ years had lower HbAlc values than those with a disease duration lower than $<2$ years, as those on poor glycaemic control were probably switched to the next superior treatment step. In contrast, glycaemic control among patients on insulin (alone or in combination) worsened as the duration of disease increased, probably because they are at the last treatment step and only intensive management with multiple insulin doses under endocrinologist supervision may improve control.

This study has strengths and limitations worth mentioning. The main strength is that we used a large outpatient database that, although not completely representative of other areas of Spain, is indicative of the trends of general practitioners' practices in a real-life clinical setting. However, this was a retrospective study subject to errors in data recording. For instance, the percentage of missing values for HbA1c was 35\% in 2007 and decreased to $25 \%$ in 2013, although this would apply equally to all study periods, therefore not affecting the conclusions of the study. Moreover, we were not able to assess whether the change in prescribed treatments over time was driven by patients' needs and characteristics (eg, prior low tolerability or effectiveness), and we cannot therefore claim a causal effect. Finally, we could not assess whether doses were appropriately chosen, and we did not consider data on prescriptions within the same therapeutic class.

\section{CONCLUSIONS}

Although the intensity of pharmacological antidiabetic treatment of T2DM increased substantially during 20072013 in Catalonia, there was no evidence that this was accompanied by a positive change in the degree of glycaemic control. This reveals shortcomings in the primary healthcare system that could be tackled through more intensive educational programmes for physicians oriented to the individualisation of glycaemic goals and prioritising more intensive treatments in younger patients.

\footnotetext{
Author affiliations

${ }^{1}$ DAP-Cat group. Unitat de Suport a la Recerca Barcelona Ciutat, Institut Universitari d'Investigació en Atenció Primària Jordi Gol (IDIAP Jordi Gol), Barcelona, Spain

${ }^{2}$ Centro de Investigación Biomédica en Red de Diabetes y Enfermedades Metabólicas Asociadas (CIBERDEM), Instituto de Salud Carlos III (ISCIII), Spain
}

${ }^{3}$ Primary Health Care Center La Mina, Gerència d’Àmbit d'Atenció Primària Barcelona Ciutat, Institut Català de la Salut, Sant Adrià de Besòs, Spain ${ }^{4}$ Primary Health Care Center Raval Sud, Gerència d'Àmbit d'Atenció Primària Barcelona Ciutat, Institut Català de la Salut, Barcelona, Spain

${ }^{5}$ Universitat Internacional de Catalunya, Epidemiologia i Salut Pública, Sant Cugat, Spain

${ }^{6}$ Department of Endocrinology \& Nutrition, Health Sciences Research Institute \& Hospital Universitari Germans Trias i Pujol, Badalona, Spain

Acknowledgements The authors acknowledge Mònica Gratacòs and Amanda Prowse for providing support in manuscript preparation and editing. CIBER of Diabetes and Associated Metabolic Diseases (CIBERDEM) is an initiative from Instituto de Salud Carlos III.

Contributors MM-C and JF-N wrote the manuscript and contributed equally to this study. JR managed the database, performed the statistical analyses and contributed to the discussion. JF-N, MM-C and DM conceived the study, participated in the study design, contributed to data cleaning, analysis and interpretation, reviewed/edited the manuscript and contributed to the discussion. MM-C had full access to all data in the study and takes responsibility for the integrity of data and the accuracy of the data analysis.

Funding This study was funded by Institut Universitari d'Investigació en Atenció Primària Jordi Gol (IDIAP Jordi Gol), and an unrestricted grant provided by Astra Zeneca.

Disclaimer The funding sources had no role in the design and conduct of the study; collection, management, analysis and interpretation of the data; or preparation, review or approval of the manuscript.

Competing interests None declared.

Ethics approval Ethics Committee of the Primary Health Care University Research Institute (IDIAP) Jordi Gol.

Provenance and peer review Not commissioned; externally peer reviewed.

Data sharing statement No additional data are available.

Open Access This is an Open Access article distributed in accordance with the Creative Commons Attribution Non Commercial (CC BY-NC 4.0) license, which permits others to distribute, remix, adapt, build upon this work noncommercially, and license their derivative works on different terms, provided the original work is properly cited and the use is non-commercial. See: http:// creativecommons.org/licenses/by-nc/4.0/

\section{REFERENCES}

1. International Diabetes Federation. IDF Diabetes Atlas. 6th edn. Brussels, Belgium: International Diabetes Federation, 2013.

2. Turner RC, Cull CA, Frighi V, et al. Glycemic control with diet, sulfonylurea, metformin, or insulin in patients with type 2 diabetes mellitus: progressive requirement for multiple therapies (UKPDS 49). UK Prospective Diabetes Study (UKPDS) Group. JAMA 1999;281:2005-12.

3. Bailey CJ. The current drug treatment landscape for diabetes and perspectives for the future. Clin Pharmacol Ther 2015;98:170-84.

4. Holman RR, Paul SK, Bethel MA, et al. 10-year follow-up of intensive glucose control in type 2 diabetes. $N$ Engl J Med 2008;359:1577-89.

5. Inzucchi SE, Bergenstal RM, Buse JB, et al. Management of hyperglycemia in type 2 diabetes, 2015: a patient-centered approach: update to a position statement of the American Diabetes Association and the European Association for the Study of Diabetes. Diabetes Care 2015;38:140-9.

6. Baviera M, Monesi L, Marzona I, et al. Trends in drug prescriptions to diabetic patients from 2000 to 2008 in Italy's Lombardy region: a large population-based study. Diabetes Res Clin Pract 2011;93:123-30.

7. Chang $\mathrm{CH}$, Jiang YD, Chung $\mathrm{CH}$, et al. National trends in anti-diabetic treatment in Taiwan, 2000-2009. J Formos Med Assoc 2012;111:617-24.

8. Leal I, Romio SA, Schuemie M, et al. Prescribing pattern of glucose lowering drugs in the United Kingdom in the last decade: a focus on the effects of safety warnings about rosiglitazone. Br J Clin Pharmacol 2013;75:861-8. 
9. Turner LW, Nartey D, Stafford RS, et al. Ambulatory treatment of type 2 diabetes in the U.S., 1997-2012. Diabetes Care 2014;37:985-92.

10. Strøm H, Selmer R, Birkeland KI, et al. No increase in new users of blood glucose-lowering drugs in Norway 2006-2011: a nationwide prescription database study. BMC Public Health 2014;14:520.

11. Oishi M, Yamazaki K, Okuguchi $F$, et al. Changes in oral antidiabetic prescriptions and improved glycemic control during the years 20022011 in Japan (JDDM32). J Diabetes Investig 2014;5:581-7.

12. Hampp C, Borders-Hemphill V, Moeny DG, et al. Use of antidiabetic drugs in the U.S., 2003-2012. Diabetes Care 2014;37:1367-74.

13. Zaharan NL, Williams D, Bennett K. Prescribing of antidiabetic therapies in Ireland: 10-year trends 2003-2012. Ir J Med Sci 2014;183:311-18.

14. Clemens KK, Liu K, Shariff S, et al. Secular trends in antihyperglycaemic medication prescriptions in older adults with diabetes and chronic kidney disease: 2004-2013. Diabetes Obes Metab 2016;18:607-14.

15. Sharma M, Nazareth I, Petersen I. Trends in incidence, prevalence and prescribing in type 2 diabetes mellitus between 2000 and 2013 in primary care: a retrospective cohort study. BMJ Open 2016;6: e010210.

16. Pornet $\mathrm{C}$, Bourdel-Marchasson I, Lecomte $\mathrm{P}$, et al. Trends in the quality of care for elderly people with type 2 diabetes: the need for improvements in safety and quality (the 2001 and 2007 ENTRED surveys). Diabetes Metab 2011;37:152-61.

17. Mancera-Romero J, Hormigo-Pozo A, Fernández-Arquero J, et al. [Use of glucose-lowering drugs in a primary care setting in Malaga during the years 2008-2012]. Semergen 2014;40:4-11.

18. Lawrenson R, Williams $T$, Farmer R. Clinical information for research; the use of general practice databases. J Public Health Med 1999;21:299-304.

19. Vinagre I, Mata-Cases M, Hermosilla E, et al. Control of glycemia and cardiovascular risk factors in patients with type 2 diabetes in primary care in Catalonia (Spain). Diabetes Care 2012;35:774-9.

20. Mata-Cases M, Mauricio D, Vinagre I, et al. Treatment of hyperglycaemia in type 2 diabetic patients in a primary care population database in a Mediterranean area (Catalonia, Spain). J Diabetes Metab 2014;5:338.

21. Franch-Nadal J, Mata-Cases M, Vinagre I, et al. Differences in the cardiometabolic control in type 2 diabetes according to gender and the presence of cardiovascular disease: results from the eControl study. Int J Endocrinol 2014;2014:131709.

22. Rodriguez-Poncelas A, Miravet-Jiménez S, Casellas A, et al. Prevalence of diabetic retinopathy in individuals with type 2 diabetes who had recorded diabetic retinopathy from retinal photographs in Catalonia (Spain). Br J Ophthalmol 2015;99:1628-33.

23. Barrot-de la Puente J, Mata-Cases M, Franch-Nadal J, et al. Older type 2 diabetic patients are more likely to achieve glycaemic and cardiovascular risk factors targets than younger patients: analysis of a primary care database. Int J Clin Pract 2015;69:1486-95.

24. Mata-Cases M, Casajuana M, Franch-Nadal J, et al. Direct medical costs attributable to type 2 diabetes mellitus: a population-based study in Catalonia, Spain. Eur J Health Econ 2015. Published Online First: 5 Nov 2015. doi:10.1007/s10198-015-0742-5

25. Ruiz-Tamayo I, Franch-Nadal J, Mata-Cases M, et al. Noninsulin antidiabetic drugs for patients with type 2 diabetes mellitus: are we respecting their contraindications? J Diabetes Res 2016;2016:7502489.

26. Mata-Cases M, Mauricio D, Franch-Nadal J. Clinical characteristics of type 2 diabetic patients on basal insulin therapy with adequate fasting glucose control that do not achieve glycated hemoglobin targets. J Diabetes 2016. Published Online First: 8 Jan 2016. doi:10.1111/1753-0407.12373.

27. Goberna R, Aguilar-Diosdado M, Santos-Rey K, et al. Consensus document for the harmonization of $\mathrm{HbA} 1 \mathrm{c}$ results in Spain. Av Diabetol 2009;25:35-7.

28. Mata-Cases M, Cos-Claramunt FX, Morros R, et al. Abordatge de la diabetis mellitus tipus 2 [online]. 2010; Guies de pràctica clínica, num 15. http://www.gencat.cat/ics/professionals/guies/diabetis/ diabetis.htm (accessed 27 Jun 2014).

29. Avilés F, MB L, Coma Redon E, et al. Sistema de Información de los Servicios de Atención Primaria (SISAP). La experiencia 2006-2009 del Institut Català de la Salut (ICS). RISAI 2010;2:1-17.

30. Alemán JJ, Artola S, Franch J, et al. Recomendaciones para el tratamiento de la diabetes mellitus tipo 2: control glucémico. Diabetes Práctica 2014;5:1-48.

31. Clemens KK, Shariff S, Liu K, et al. Trends in antihyperglycemic medication prescriptions and hypoglycemia in older adults: 20022013. PLOS ONE 2015;10:e0137596.

32. Rafaniello C, Arcoraci V, Ferrajolo C, et al. Trends in the prescription of antidiabetic medications from 2009 to 2012 in a general practice of Southern Italy: a population-based study. Diabetes Res Clin Pract 2015;108:157-63

33. Kohro T, Yamazaki T, Sato $\mathrm{H}$, et al. Trends in antidiabetic prescription patterns in Japan from 2005 to 2011. Int Heart J 2013;54:93-7.

34. Sinclair AJ, Paolisso G, Castro M, et al., European Diabetes Working Party for Older People. European Diabetes Working Party for Older People 2011 clinical guidelines for type 2 diabetes mellitus. Executive summary. Diabetes Metab 2011;37(Suppl 3):S27-38.

35. NICE (National Institute for Health and Clinical Excellence). Clinical guideline CG87. Type 2 diabetes: the management of type 2 diabetes. Last updated December 2014. http://guidance.nice.org.uk/ CG87/NiceGuidance/pdf/English

36. Nissen SE, Wolski K. Effect of rosiglitazone on the risk of myocardial infarction and death from cardiovascular causes. $N$ Engl $J$ Med 2007;356:2457-71

37. Swinnen SG, Hoekstra JB, DeVries JH. Insulin therapy for type 2 diabetes. Diabetes Care 2009;32(Suppl 2):S253-9.

38. Lewis JD, Ferrara A, Peng T, et al. Risk of bladder cancer among diabetic patients treated with pioglitazone: interim report of a longitudinal cohort study. Diabetes Care 2011;34:916-22.

39. Ryder RE. Pioglitazone has a dubious bladder cancer risk but an undoubted cardiovascular benefit. Diabet Med 2015;32:305-13.

40. Karagiannis T, Paschos $\mathrm{P}$, Paletas $\mathrm{K}$, et al. Dipeptidyl peptidase-4 inhibitors for treatment of type 2 diabetes mellitus in the clinical setting: systematic review and meta-analysis. BMJ 2012;344:e1369.

41. Mata-Cases M, Benito-Badorrey B, Roura-Olmeda P, et al. Clinical inertia in the treatment of hyperglycemia in type 2 diabetes patients in primary care. Curr Med Res Opin 2013;29:1495-502.

42. Alonso-Morán E, Orueta JF, Esteban JIF, et al. Prevalence and quality of care indicators of type 2 diabetes in the population of the Basque Country (Spain). Av Diabetol 2015;31:72-9.

43. Subramanian S, Hirsch IB. Personalized diabetes management: moving from algorithmic to individualized therapy. Diabetes Spectr 2014;27:87-91.

44. Khunti K, Wolden ML, Thorsted BL, et al. Clinical inertia in people with type 2 diabetes: a retrospective cohort study of more than 80,000 people. Diabetes Care 2013;36:3411-17.

45. Khunti K, Nikolajsen A, Thorsted BL, et al. Clinical inertia with regard to intensifying therapy in people with type 2 diabetes treated with basal insulin. Diabetes Obes Metab 2016;18:401-9. 